\title{
A educação de Paulo Freire - Andarilho DA UTOPIA - EM DIFERENTES CONTEXTOS
}

\author{
IVANILDE Apoluceno de Oliveira \\ TÂNIA Regina Lobato dos Santos \\ Universidade do Estado do Pará (UEPA), Belém, Pará, Brasil
}

\begin{abstract}
Resumo: Paulo Freire em sua andarilhagem pelo mundo contribuiu para o sistema educacional e programas educativos de alguns países, bem como subsidiou novos aportes teóricos e influenciou, sobretudo na América Latina, a concepção de educação popular nos anos 60. Neste artigo objetiva-se analisar a influência da educação de Paulo Freire em diferentes contextos, proveniente dessa sua andança pelo mundo. Consiste em um estudo bibliográfico incluindo obras de Paulo Freire e de autores que estudam o seu pensamento educacional no Brasil e em outros países. Neste artigo apresentamos Paulo Freire como inspirador de movimento libertador e trazemos o debate sobre a influência da educação popular de Paulo Freire em diferentes contextos sociais, culturais e educacionais.

Palavras-chave: Paulo Freire. Educação Popular. Diferentes contextos. Andarilhagem no mundo.
\end{abstract}

"Não é possível ter liberdade cultural enquanto a 'cultura do silêncio' prevalecer na América Latina". Paulo Freire (2010, p. 345)

\section{INTRODUÇÃO}

Paulo Freire em sua andarilhagem pelo mundo contribuiu com o seu pensamento educacional para temas como a educação popular, a 
alfabetização de jovens e adultos, a pedagogia crítica libertadora, a educação indígena, os estudos da interculturalidade, entre outros, em diferentes países.

A constituição do pensamento político-pedagógico de Paulo Freire tem como lócus principal o Brasil e a América Latina da década de 60 e a partir dos anos 70, chega à África e dissemina-se por todo o mundo, influenciando, inclusive países da Europa e da América do Norte. Essa disseminação teve como ponto de partida e referência fundamental o livro Pedagogia do Oprimido, embora aos poucos os estudiosos deste pensamento fossem descobrindo sua magnitude, sua complexidade e sua heterogeneidade (SCOCUGLIA, 2001, p. 323).

Os temas da educação popular na perspectiva freireana circularam em diferentes contextos: nos movimentos sociais, nas universidades, nos centros de investigações e nas organizações de base das igrejas, entre outras. Torres (2001) e Jara (2009) destacam que a filosofia educacional de Paulo Freire inicia no Brasil e circula na América Latina, Estados Unidos, Canadá e África, enriquecendo-se, sobretudo, no seu período de exílio.

Essa filosofia em construção está presente desde os seus primeiros escritos, marcados pela intensa experiência no Brasil dos anos cinquenta e sessenta, e foi enriquecendo-se ao longo de seu exílio, sempre recriando seu pensamento diante de cada novo desafio: primeiro na Bolívia, depois no Chile, onde esteve de 1964 a 1969, posteriormente nos Estados Unidos, e depois trabalhando com o Conselho Mundial das Igrejas em Genebra de 1970 a 1980, parte de cujo tempo passou vinculado à experiência educativa de Guiné Bissau, até voltar novamente à América Latina, especialmente no seu último período de compromisso político, pedagógico e pessoal no Brasil (JARA, 2009, p. 38).

Neste artigo analisamos a influência da educação de Paulo Freire em diferentes contextos, proveniente de sua andarilhagem pelo mundo, destacando-o como inspirador de movimentos libertadores e focando para a contribuição de seu pensamento educacional para sistemas e programas de Educação de Jovens e Adultos na África, o pensamento crítico e a educação intercultural nos Estados Unidos e na América Latina e a educação popular e o discurso anticolonial no contexto latino-americano.

Consiste em um recorte de uma pesquisa de campo de abordagem qualitativa, financiada pelo Conselho Nacional de Desenvolvimento Científico e Tecnológico (CNPq) e concluída em 2016, sobre a presença de Paulo Freire nos contextos da América do Norte e América Latina. Os dados apresentados têm por base o estudo bibliográfico incluindo obras de Paulo Freire e de autores que estudam o seu pensamento educacional em diferentes contextos. 


\section{PAULo FreIRE: INSPIRAdOR DE MOVIMENTOS LIBERTADORES}

No Brasil, segundo Brandão (2002), as iniciativas de educação popular nos anos 60 são oriundas de uma frente polissêmica de ações envolvendo espaços e instituições diversas, tais como: grêmios estudantis, igrejas católicas, sindicatos, movimentos populares e o próprio estado, como na Campanha Nacional de Alfabetização.

Entre os Movimentos de Educação Popular no Brasil destacam-se: Movimento de Cultura Popular - MCP (Recife); Campanha "De pé no chão também se aprende a ler"; Angicos - do Governo do Rio Grande do Norte (Natal/Rio Grande do Norte); e Campanha de Educação Popular da Paraíba CEPLAR (João Pessoa), entre outras (SCOCUGLIA, 1997) que desenvolveram experiências da cultura popular.

Pela primeira vez surge a proposta de uma educação que é popular não porque o seu trabalho se dirige a operários e camponeses excluídos prematuramente da escola seriada, mas porque o que ela "ensina" vincula-se organicamente com a possibilidade de criação de um saber popular, através da conquista de uma educação de classe, instrumento de uma nova hegemonia (BRANDÃO, 1984, p. 70).

Ainda, segundo este autor, nos anos 70 e 80, a educação popular ganha uma dimensão latino-americana e, posteriormente, internacional. Há uma tendência de se multiplicar os movimentos e as frentes de algumas modalidades de ação popular.

Movimentos sociais de gênero, de etnia, de cultura, de luta pelos direitos humanos, de ação comunitária, de vocação ambientalista, em muitos casos se reconhecem como incorporando, de algum modo, o espírito originário e o ideário das práticas atuais da educação popular (BRANDÃO, 2002, p. 151).

Um exemplo dessa internacionalização de Paulo Freire nos movimentos sociais é o Movimento Zapatista, no México, que utiliza entre os seus referenciais Paulo Freire.

Guillermo Michel (2001), ao tratar da filosofia dos Zapatistas, cita Freire como um autor, entre outros como Dussel e Levinas, que dialoga com os saberes políticos Zapatistas. Explica que os opressores não aceitam que os zapatistas possam estar propondo algo novo, uma utopia possível e que estão longe de realizar a vocação ontológica de ser mais. Dessa forma, a humanização proposta por Freire afirma que:

Com toda razão, Paulo Freire adverte que: "somente podem ser proféticos os que anunciam e denunciam comprometidos permanentemente com 
um processo radical de transformação para que os homens [e mulheres] possam ser mais. Os homens opressores, os reacionários não podem ser utópicos. Não podem ser proféticos, e, portanto, não podem ter esperança" (MICHEL, 2001, p. 73).

Além da questão da humanização, o autor trata, também, de Paulo Freire, os conceitos de conscientização e diálogo.

Parece-me necessário agregar a figura serena e luminosa de Paulo Freire, cuja Pedagogia do Oprimido (como havia mencionado antes) constitui uma espécie de "manifesto" teórico-prático, para empreender a conscientização e o diálogo. [...] poucas vezes o mencionam como um dos utopistas mais importantes de nossa época. Porém basta compreender o que para ele significa conscientização, para perceber, ao mesmo tempo, o grande alcance de sua utopia (MICHEL, 2001, p. 122).

Apresenta, então, o conceito de conscientização ligado ao de utopia, tendo por base a mensagem de Paulo Freire.

A conscientização nos convida a assumir uma posição utópica frente ao mundo, posição que converte o conscientizado em "fator utópico". Para mim, o utópico não é o irrealizável. A utopia não é o idealismo (não se trata de sonhar despertos), é a dialetização dos atos de denunciar e anunciar: $o$ ato de denunciar a estrutura desumanizante e de anunciar a estrutura humanizante. Por esta razão a utopia é também compromisso histórico [...] A conscientização está evidentemente ligada à utopia, implica a utopia... (MADRI, 1972 apud MICHEL, 2001, p. 122-123).

O próprio subcomandante Marcos, em um de seus discursos, clama "por uma educação libertadora! Por uma educação científica e popular! Coloco-me a serviço do meu povo" (MARCOS, 2004 apud MORETTI, 2010, p. 442), evidenciando ser a educação freireana parte da luta política do Movimento Zapatista.

Michel trata tanto da influência de Freire entre os Zapatistas como destaca a importância de Paulo Freire para a criação da utopia latino-americana:

Há tempo esquecido por pedagogos, por educadores e por filósofos, considero, entretanto, que Paulo Freire está chamado a ser o inspirador de um movimento de libertação muito mais amplo que ele pode realizar no transcurso de sua vida. Suas numerosas obras e sua práxis revolucionária podem chegar a ser alimento de quem desejamos comprometer-nos a criar - em comunhão com os oprimidos - a utopia latinoamericana... A utopia a que agora nos convidam índios da América, especialmente os Tzeltales, Choles, Tzotziles, Mames, Zoques e Tojolabales do sudoeste mexicano, identificados coletivamente como o Votán-Zapata, "guardião e coração do povo"; porque 
esta Utopia não brota de uma imaginação desbordada, nem é uma ilusão idiota ou uma fantasia estridente própria de sonhares com a cabeça nas nuvens (MICHEL, 2001, p. 123).

Paulo Freire, então, é visto por Michel (2001) como inspirador não só do Movimento Zapatista, mas de um movimento utópico de libertação mais amplo, latino-americano. E, para Carrillo (2009, p. 10): “Freire já não é patrimônio exclusivo das pedagogias alternativas e sim dos movimentos e pensamento emancipador mundial."

Carrillo (2011) chama atenção para a influência do pensamento educacional de Paulo Freire para os movimentos cristãos e para a Teologia da Libertação:

A militância cristã de Freire e o caráter humanista de sua proposta fez com que fosse acolhida na Igreja; primeiro o MEB do Brasil assume sua metodologia e posteriormente a Conferência Episcopal de Medellin (1968); deste modo, as abordagens e a metodologia de Freire influenciam no que posteriormente seria a Teologia da Libertação. Muitos religiosos e cristãos comprometidos com os pobres viram na Educação Conscientizadora, a metodologia mais coerente com suas ações pastorais e educativas (CARRILLO, 2011, p. 28).

Frei Betto (1985a, p. 26), em diálogo com Freire, afirma que a filosofia personalista o aproximou de Paulo Freire: "nós dois fomos discípulos da filosofia personalista do Padre Vaz [...]". Ressalta a importância da filosofia personalista para a criação de "uma nova postura epistemológica" de encarar os problemas brasileiros nos anos 60 , observada não só na lgreja, mas também na educação, principalmente com a contribuição de Paulo Freire (OLIVEIRA, 2003).

Explica Oliveira (2003, p. 41) que Freire coloca em questão:

o papel alienante, de "mitificação da consciência" que a Igreja tem desenvolvido na história da humanidade e aponta para uma nova prática emergente com os teólogos latino-americanos que "engajando-se historicamente, cada vez mais com os oprimidos, defendem hoje uma teologia política da libertação". Corrobora as suas ideias e os considera "capazes de denunciar a 'ordem'que os esmaga e, na práxis da transformação desta 'ordem', anunciar um mundo novo a ser refeito constantemente".

Para Freire (1993c, p. 112), “Deus é uma 'Presença na História', mas uma Presença que não nos proíbe de fazer História. É uma Presença que não nos imobiliza para que se faça a História que nos cabe fazer"e a Igreja profética teria como temática "a que emerge das condições objetivas das sociedades dependentes, exploradas, invadidas. A que emerge da necessidade da 
superação real das contradições que explicam tal dependência. A que vem do desespero das classes sociais oprimidas" (FREIRE, 1982, p. 126). Sendo assim, Freire considera que:

ser cristão não significa necessariamente ser reacionário, como ser revolucionário não significa ser'demoníaco'. Ser revolucionário significa estar contra a opressão, contra a exploração, em favor da libertação das classes oprimidas, em termos concretos e não em termos idealistas (FREIRE, 1982, p. 113).

Freire aponta para um novo papel da igreja, o de assumir uma posição de classe, um compromisso com os pobres, com a população oprimida, que constitui também pressupostos da Teologia da Libertação. Conforme Oliveira (2003, p. 42):

Os conceitos cristãos de "amor", "diálogo" e "esperança" e os marxistas "dialética", "história", "práxis" e "alienação" estão presentes tanto em Freire quanto na Teologia da Libertação. O caráter revolucionário da educação libertadora, dimensionando a educação como ato gnosiológico e político se aproxima da dimensão política da ação da igreja, com a eliminação da "neutralidade" e a afirmação de um compromisso político com "os oprimidos", com os pobres. A opção pelos pobres pela Igreja significa uma opção política.

Desta forma, a Teologia da Libertação tem proximidade com a educação humanista e libertadora de Paulo Freire ao assumir o compromisso político com os pobres.

\section{Influência de Paulo Freire em Sistemas e Programas Educacionais}

Paulo Freire contribuiu de forma significativa para a construção de projetos e programas de educação em diversos países, principalmente de programas de alfabetização e de educação de jovens e adultos. Torres (2001, p. 37) cita alguns destes Programas: "as campanhas de alfabetização em GuinéBissau; São Tomé e Príncipe, Granada, Nicarágua e México, e os programas de educação de jovens e adultos na Tanzânia e Sul da África.

Na África, Paulo Freire prestou assessoria a projetos de educação. Ana Maria Freire (2006, p. 221) destaca, em relação a esse trabalho de assessoria, que:

Esses povos conheceram o trabalho de Paulo quando se empenhavam, nos anos 60, em livrar-se das garras do colonialismo, em extirpar os resquícios do opressor que tinha feito de muitos dos corpos negros africanos cabeças brancas de portugueses além-mar. Esses povos queriam e precisavam libertar-se da 'consciência hospedeira da opressão', como tanto denunciou 
Paulo formando seus homens, mulheres e crianças para serem cidadãos de seus países e do mundo.

Em Moçambique, a educação libertadora de Paulo Freire viabiliza superar a pedagogia da escola colonial. Oliveira (2010) apresenta o relato feito por Ivalia sobre a experiência de alfabetização de adultos por um grupo de missionários em Nampula, com a filosofia freireana, e que evidencia a importância da proposta de educação libertadora contra a pedagogia da escola colonial vigente em Moçambique.

Foi em outubro de 1974 que as atividades de alfabetização promovidas pelo grupo, de que eu fazia parte, tiveram início. A nossa inspiração vinha da atual província de Manica, onde, anteriormente, um grupo de missionários tinham realizado uma experiência de alfabetização de adultos, no bairro da Soalpo, com o envolvimento de operários da fábrica têxtil Textafrica, seguindo o método de Paulo Freire [...]. A mensagem veiculada pelo método de Paulo Freire era para nós uma novidade que identificávamos com a própria revolução da FRELIMO' que acabava de derrubar o colonialismo. A nossa formação, como alfabetizadores, centrava-se no estudo das ideias-força e no método expressos nas reflexões filosóficas de Paulo Freire e nas suas críticas à concepção bancária de educação [...] Estas ideias-força se impunham a nós como alternativa à educação colonial, da qual ainda não tínhamos saído. Promover uma ação educativa neste sentido era contribuir para a elevação da consciência da população face aos desafios que se impunham com a liberdade e com a independência que se avizinhava. Estávamos convencidos de que a alfabetização pela conscientização estava de acordo com as estratégias que a FRELIMO iria seguir, após tomar o poder. A crítica sobre a concepção bancária da educação merecia a nossa maior atenção, porque punha em causa toda a pedagogia da escola colonial (IVALA, 2000 apud OLIVEIRA, 2010, p. 43-44).

A educação de Paulo Freire, por seu caráter político, conforme Nóvoa (1998), influenciou na África, as políticas educacionais de países que se tornaram independentes. Entretanto, aponta Braço (2012, p. 141), para a existência de uma relação de união entre a África e Paulo Freire:

A união entre a África e Paulo Freire é longínqua. Pode-se até afirmar que muitas lideranças africanas nutriram-se da presença e do pensamento de Freire na sua formação de suas identidades como revolucionários e, ainda, muitos educadores africanos, no período pós-independência, sustentaram-se das ideias e dos ideais de Freire na modelagem dos sistemas educativos, dos respectivos países. Mas, ao mesmo tempo, é legítimo afirmar que as "falas" de Paulo Freire misturam-se com as experiências por si vividas na África, pois não é difícil perceber influências africanas no seu modo de ser, estar, fazer e conviver. 
Isto significa que houve também, por parte de Paulo Freire, uma aprendizagem nas experiências com os processos de libertação na África. Influências mútuas entre Paulo Freire, Amilcar Cabral e Julius Nyerere². Na África, Freire encontrou um cenário político que possibilitou radicalizar e emancipar a sua educação libertadora (BRAÇO, 2012).

No Chile, Isabel Hernández (1981) realizou uma experiência de educação indígena com aplicação bilíngue do método de Paulo Freire, como parte do Programa de Mobilização Cultural do povo Mapuche. É uma atividade alfabetizadora que tem como ponto de partida a motivação por meio de símbolos geradores (desenhos e palavras), com debates sobre a cultura Mapuche, seguida da reflexão, leitura e escrita das palavras geradoras, sendo considerada uma tarefa revolucionária.

Gadotti (2011) destaca que o Chile e a África "radicalizaram" o pensamento de Freire, que amadureceram suas reflexões e experiências nascidas em seu país de origem, elaborando uma fecunda produção intelectual.

As experiências de Paulo Freire na África, remodelaram sua pedagogia. Inserido em processos de reconstrução nacional, realizou a simbiose entre educação e em forças produtivas, incorporando o trabalho como princípio educativo. Essa evolução no seu pensando ele a deve ao seu encontro com a África e foi muito importante nas obras escritas posteriormente (GADOTTI, 2011, p. 16).

Dessa forma, Freire não só influenciou, por meio de seu pensamento educacional, intelectuais e educadores dos países que viveu no exílio, como também aprendeu e incorporou em seu discurso pedagógico as experiências vividas.

\section{Pensamento crítico e intercultural nos Estados Unidos e América LATINA}

Considera Carrillo (2009, p. 11) que"a obra de Paulo Freire ocupa um lugar central e é um referencial imprescindível ao processo de reconstrução do pensamento emancipador". Nos Estados Unidos, há influência de Paulo Freire na pedagogia crítica de Henry Giroux e Carlos Alberto Torres, bem como no pensamento crítico e multicultural de Peter McLaren. Na América Latina, autores como Carlos Nuñez, Alfredo Ghiso, Sergio Martinic, Oscar Jara, entre outros, têm retomado e recriado as ideias educacionais de Paulo Freire.

O exílio possibilitou a Freire internacionalizar o seu pensamento educacional, como também aprendeu, na convivência com a diferença e a 
diversidade cultural, a compreender melhor e a incorporar em seu discurso pedagógico o debate sobre o multiculturalismo e questões referentes às diferenças de classe, gênero e etnia.

Nóvoa (1998) explica que nos Estados Unidos, Freire constitui-se em uma referência importante de grupos de intelectuais universitários, cuja agenda política incluía as questões de classe, de raça e de gênero. Destaca, ainda, ser o interesse desses intelectuais o princípio freireano de lutar contra todas as formas de discriminação social.

Peter McLaren (2007, p. 01) afirma sobre Paulo Freire:

é, de longe, o mais importante educador crítico lido nos EUA. Seu trabalho é consistentemente adotado por estudantes em universidades, por professores do ensino fundamental e médio, por estudantes de magistério e por membros de grupos de ação social e de novos movimentos sociais, ou seja, por grupos do setor não-formal. Seu trabalho é encontrado nas aulas, nas universidades, em estudos de alfabetização, na teologia, na pedagogia crítica, e através das ciências humanas.

McLaren, então, aponta para a abrangência de práticas e campos de saber em que Paulo Freire é referência nos Estados Unidos e explica também como Freire está presente em suas produções:

Eu simplesmente tentei integrar pensadores norte-americanos mais contemporâneos a essa mistura - teóricos feministas e multiculturalistas, muitos deles da comunidade intelectual afro-americana e latino-americana. Comecei a incorporar Gramsci e muitos dos pensadores marxistas ocidentais (por exemplo, da Escola de Frankfurt) em meu trabalho. Claro a tradição do pensamento indígena por todas as Américas foi - e ainda é - extremamente importante. E Freire foi sempre fundamental para o desenvolvimento de minha pedagogia crítica (2007, p. 01).

A interculturalidade no pensamento de Paulo Freire vai ter influência também na América Latina, em especial, no Brasil.

Serna $(2009$, p. 96) destaca na educação popular de Paulo Freire o vínculo com a interculturalidade, cujo suporte teórico é o diálogo.

O diálogo nos processos de interculturalidade é indispensável, é condição para superar o desenho de individualização fragmentada, consumista, egoísta e possessiva, de igual forma, como essencial se reconhece nos processos de preparação política a de intervenção social com a educação popular.

Oliveira (2010) afirma que a influência da educação popular, de base Freireana, na construção da educação intercultural no Brasil é destacada por autores como: Candau (2008, 2002), Fleuri (2003), Walsh (2009), entre 
outros, e alvo de estudo por Souza (2001) e Araújo (2004), o que evidencia o reconhecimento da importância do pensamento educacional de Paulo Freire para o debate da educação intercultural.

Um dos pontos de referência desta contribuição é o fato de nos anos 60 a educação de Paulo Freire focar como centro de debate a cultura e o engajamento ético-político com os segmentos sociais oprimidos, direcionando as práticas pedagógicas para o exercício crítico da cidadania e para a afirmação tanto destes atores sociais como sujeitos, como de sua cultura.

A educação popular freireana propõe uma educação que valorize e respeite as diferenças culturais e os saberes e as experiências de vida dos sujeitos, considerando que:

compreender a realidade do oprimido, refletida nas diversas formas de produção cultural - linguagem, arte, música -, leva a uma compreensão melhor da expressão cultural mediante a qual as pessoas exprimem sua rebeldia contra os dominantes. Essas expressões culturais representam, também, o nível de luta possível contra a opressão (FREIRE; MACEDO, 1990, p. 85).

Para Oliveira (2010), na denúncia da opressão (desumanização) e no anúncio da libertação (humanização) emerge a discussão sobre a interculturalidade nas obras de Paulo Freire, que perpassa pelo debate sobre as diferenças e as especificidades das diversas formas de opressões. A questão da diferença está vinculada à opressão social, sendo dimensionada por Paulo Freire como um problema político.

Desta forma, para Paulo Freire a diferença é uma questão política, sendo necessário levar em consideração a multiplicidade de experiências opressivas para que possam ser criadas estruturas coletivas de libertação, na busca de superação de todas as formas de opressão. Mas, ele destaca que:

por mais que, nesta ou naquela sociedade, por motivos históricos, sociais, culturais, econômicos seja visivelmente sublinhada a importância da raça, da classe, do sexo, na luta de libertação, é preciso que evitemos cair na tentação de reduzir a luta inteira a um desses aspectos fundamentais. $O$ sexo só não explica tudo. A raça só, tampouco. A classe só, igualmente (FREIRE, 1993b, p. 94-95).

Oliveira (2010) explica que Paulo Freire situa a multiculturalidade no processo de libertação, que não se caracteriza pela justaposição de culturas nem pelo poder exacerbado de uma sobre as outras, mas se fundamenta: 
na liberdade conquistada, no direito assegurado de mover-se cada cultura no respeito uma da outra, correndo risco livremente de ser diferente, sem medo de ser diferente, de ser cada uma "para si", somente como se faz possível crescerem juntas (FREIRE, 1993a, p. 156).

Para Gustsack (2008), o tema da diferença está presente em Paulo Freire quando debate o compromisso do ser humano com o processo de humanização do mundo, bem como pelo reconhecimento e respeito à diferença, que abarca um diálogo mais amplo, que pode ser percebido em dimensões interculturais.

A interculturalidade em Paulo Freire, então, tem como referência a compreensão de que há diferenças entre as culturas e tensões entre elas e a valorização das relações interculturais, que pressupõe a dialogicidade e a eticidade. Relações de respeito que se dimensionem como uma síntese cultural, viabilizando a dinâmica criadora do processo de produção cultural. Desta forma, passa a ser importante considerar-se o processo de hibridização cultural na produção cultural dos diferentes grupos sociais.

Assim, a filosofia educacional de Paulo Freire vem contribuindo para o avanço do pensamento crítico e emancipador, com a construção de novos aportes teóricos sobre a educação.

\section{Educação popular e discurso anticolonial de Paulo Freire na América LATINA}

Para Torres (2001), a educação popular surge da análise política e social das condições de vida dos pobres e de seus problemas mais visíveis como a má nutrição, o desemprego, as enfermidades... Busca esclarecer estas condições em nível individual e coletivo, tomando por base o conhecimento prévio adquirido pelas populações. Assim, o ideário da educação popular, vinculado à noção de revolução cultural dos anos 60, é um modelo oposto à agenda neoliberal na educação latino-americana, que culmina em posturas conservadoras e capitalistas no mundo inteiro. Consiste, ainda, em uma contradição com a tradição liberal e o espírito da educação pública que predominou no continente neste século.

Magendzo (2004 apud CARRILLO, 2011, p. 12) destaca que na educação popular "Paulo Freire é a contribuição mais significativa que a América Latina teve no mundo da educação, podemos afirmar, e não querendo desqualificar ninguém, que é o único aporte real, revelador e original que contribuiu para a educação". 
Apesar de encontrar diferentes concepções de educação popular entre os teóricos latino-americanos, Carrillo (2011, p. 14) aponta um núcleo comum constitutivo da educação popular:

1. Uma leitura crítica da ordem social vigente e um questionamento sobre o papel integrador que faz parte da educação formal;

2. Uma intencionalidade política emancipadora frente à ordem social imperante;

3. Um propósito de contribuir ao fortalecimento dos setores dominados como sujeito histórico, capaz de protagonizar a mudança social;

4. Uma convicção que pela educação é possível contribuir ao êxito desta intencionalidade, atuando sobre a subjetividade popular;

5. Um afã por generalizar e empregar metodologias educativas dialógicas, participativas e ativas.

Desta forma, há uma intencionalidade política transformadora, que passa pela crítica à sociedade capitalista e ao seu sistema educativo e o desenvolvimento de propostas educativas populares com a intenção política de transformar as condições opressoras e contribuir para a construção de uma nova sociedade mais justa e democrática.

Essa base comum tem em Freire suas diretrizes fundantes. Para Carrillo (2011, p. 29):

a obra pedagógica de Freire foi mais além de seu método de alfabetização, formando as diretrizes fundantes tanto da educação popular como das pedagogias críticas. A ampla obra escrita de Freire e suas inumeráveis apresentações públicas configuram um rico universo de reflexões acerca da educação, da pedagogia e da ética libertadora.

Carrillo, tal como Torres, destaca a amplitude do pensamento educacional de Paulo Freire na América Latina.

Oscar Jara (1994) assinala algumas pistas da história da educação popular na América Latina, entre as quais "o aporte de Paulo Freire". Explica que na década de 60 a experiência e o pensamento de Paulo Freire marcam ponto fundamental de referência na história da educação popular na América Latina. “O método psicossocial de alfabetização criado por Freire se pôs em moda em quase todo o continente. $O$ mesmo se passou com o conceito de conscientização, que começou a ser usado - e segue sendo hoje - com os mais diversos significados" (JARA, 1994, p. 93).

Rivero (2009) afirma que Paulo Freire ultrapassou os limites do contexto latino-americano. A sua visão política de alfabetização está associada a uma compreensão crítica da realidade social, política e econômica, 
constituindo a alfabetização mais do que um ato de ler e escrever, ou seja, uma habilidade de ler o mundo.

Explica Jara (1994) que houve uma redefinição política da educação popular na América Latina, na medida em que os movimentos sociais impulsionaram a criação de programas e formas de educação popular com o objetivo de orientar as ações das massas no momento histórico vivido. Isto se deu no Peru, Equador, Bolívia, Panamá, El Salvador e Guatemala.

Streck (2010, p. 331) considera que "Paulo Freire representa um momento de consolidação de um pensamento pedagógico latino-americano. Suas obras constituem o núcleo de um movimento educativo que na segunda metade do século XX passou a ser reconhecido como Educação Popular". Ressalta como Jara, que houve ressignificação deste conceito por autores como Domingos Sarmiento (Argentina), José Marti (Cuba) e José Pedro Varela (Uruguai).

O autor destaca, ainda, que"com Freire, a pedagogia latino-americana ganha um caráter universal". Universalidade entendida como radicalidade, "tanto mais se vai à raiz, tanto mais se amplia o círculo de possibilidades". Aponta duas tarefas contidas na pedagogia freireana: (1) reconstruir a memória pedagógica por meio de uma "arqueologia da consciência"; e (2) recuperar as pedagogias silenciadas durante séculos de dominação. 'A 'cultura do silêncio' denunciada por Freire nas classes populares também se manifesta nos silenciamentos de práticas educativas transformadoras"(STRECK, 2010, p. 331).

Freire, então, contribui, tal como Frantz Fanon (2005), para o debate de superação da visão colonialista pedagógica e eurocêntrica, presente na história da América Latina, tomando como ponto de partida os esfarrapados do mundo.

Zitkoski (2006, p. 72) considera que “Freire e Fanon convergem para o mesmo ponto com relação à necessidade da ruptura cultural e política diante dos modelos colonialistas e opressores vindos da Europa e seus aliados". Afirma ainda o autor, que Freire comunga com as críticas ao eurocentrismo que impôs um modelo de vida alienante aos diferentes povos do mundo por meio da invasão cultural opressora e genocida às culturas diferentes do núcleo ocidental.

Oliveira (2010) explica que está presente nas obras de Paulo Freire o debate sobre o colonialismo, pela crítica que faz ao processo opressor da colonização, no qual o dominante realiza a invasão cultural e obstaculiza a participação democrática pela imposição da cultura do silêncio. Ressalta ainda a autora que no livro Cartas à Guiné-Bissau, Freire (1978) expõe que a educação colonialista visava a desafricanização dos nativos por meio do discurso ideológico da superioridade branca e essa educação mantém a cultura dos colonizadores. 
Desta forma, no processo revolucionário haveria a tarefa de se "descolonizar as mentes", ou no dizer de Amílcar Cabral, "reafricanizar as mentalidades", trabalhando-se com a transformação do sistema educacional, tendo como ponto de partida as culturas nativas. No processo educacional o educador teria de "deixar-se molhar completamente pelas'águas culturais' das massas populares, para poder senti-las e compreendê-las" (FREIRE; FAUNDEZ, 1985b, p. 109). Esse"descolonizar as mentes" visa superar as estruturas sociais de poder eurocêntricas e colonialistas. Na Pedagogia da Indignação, ao tratar sobre o descobrimento da América, Freire (2000) critica e recusa o processo de colonização:

A presença predatória do colonizador, seu incontido gosto de sobrepor-se, não apenas ao espaço físico mas ao histórico e cultural dos invadidos, seu mandonismo, seu poder avassalador sobre as terras e as gentes, sua incontida ambição de destruir a identidade cultural dos nacionais, considerados inferiores, quase bichos, nada disto pode ser esquecido quando, distanciados no tempo, corremos o risco de "amaciar" a invasão e vê-la como uma espécie de presente "civilizatório" do chamado Velho Mundo. Minha posição hoje, decorridos 500 anos da conquista [...] é a de quem não se acomoda diante da malvadeza intrínseca a qualquer forma de colonialismo, de invasão de espoliação (FREIRE, 2000, p. 73-74).

Paulo Freire critica o colonialismo, a manutenção da mentalidade colonial em práticas sociais cotidianas, sendo tarefa da educação libertadora partir dos saberes da cultura local, dos oprimidos, dando voz aos sujeitos historicamente negados.

Assim, a discussão sobre o colonialismo está presente em suas obras pela crítica ao processo opressor da colonização, no qual o dominante realiza a invasão cultural, impõe a cultura do silêncio e obstaculiza a participação democrática.

Giroux (1998) denuncia que o discurso anticolonial e pós-colonial presente no pensamento educacional de Paulo Freire se perderam na apropriação do seu pensamento nos Estados Unidos, ou seja, é ensinada a sua pedagogia sem referência ao imperialismo e sua representação cultural. Este autor também argumenta que o "trabalho de Freire deve ser lido como um texto pós-colonial", ou seja, em uma "perspectiva de ultrapassar fronteiras, reinventar tradições não inseridas no discurso de submissão, reverência e repetição" (GIROUX, 1998, p. 192).

Neste sentido, convém ressaltar que fazer referência a Freire significa trabalhar com os princípios pedagógicos de sua pedagogia. O diferencial nas ações educacionais de base freireana são os princípios do diálogo, da autonomia dos sujeitos, o desenvolvimento da criatividade, o respeito às 
diferenças e aos saberes; e na consideração da realidade social, o ensino participativo, a escuta e respeito ao dizer e conhecimento do outro. Além de que, não se pode prescindir da reflexão sobre o discurso anticolonial e pós-colonial, cuja ausência acaba por transformar o discurso educacional em discurso vazio e sem significação histórico-social.

Entender Paulo Freire como intelectual de fronteira significa dizer que seu pensamento vem se alterando em função do tempo e do contexto histórico que se encontra inserido, seja no exílio, seja na África, América Latina, América do Norte ou Europa. A atualidade do seu pensamento não se restringe a fronteiras sociais, culturais e políticas.

\section{Considerações Finals}

O pensamento teórico-metodológico de Paulo Freire, em sua andarilhagem no mundo, atravessou países e continentes, influenciando a criação de programas e práticas educacionais, contribuindo para a disseminação da educação popular, especialmente na América Latina, e para a gênese de novos aportes teóricos e temas educacionais em diversos países.

O seu legado educacional permanece pleno de desafios, porque os temas em debate, tendo como base a pedagogia do oprimido, continuam atuais, refletem contextos sociais e culturais diversos, que ainda estão em estudos e que se tem muito a pesquisar.

Como "Andarilho da Utopia", Paulo Freire espalha pelo mundo a esperança e um movimento emancipador e revolucionário, cujo objetivo, por meio do comprometimento político com as classes populares, é promover a autonomia dos sujeitos e viabilizar a transformação social.

Artigo recebido em: 08/10/2016

Aprovado para publicação em: 12/12/2016

THE PAULO FREIRE EDUCATION - WANDERER OF UTOPIA - IN DIFFERENT CONTEXTS

Abstract: Paulo Freire in his wanderings around the world contributed to the educational system and educational programs of some countries, as well as subsidized new theoretical contributions and influenced, especially in Latin America, the conception of popular education in the $60 \mathrm{~s}$. This article aims to analyze the influence of Paulo Freire education in different contexts, from his wanderings through this world. Consists of a bibliographic study, including Paulo Freire works and authors who study his educational thought in Brazil and other countries. In this article we present Paulo 
Freire as an inspiring of liberation movement and bring the debate about the influence of Paulo Freire popular education in different social, cultural and educational contexts. KeYwords: Paulo Freire. Popular Education. Different contexts. Wanderings through the world.

\section{LA EDUCACIÓN DE PAULO FREIRE - CAMINANTE DE LA UTOPÍA - EN DIFERENTES CONTEXTOS}

Resumen: Paulo Freire en sus andanzas por el mundo contribuyó con el sistema de educación y con los programas educativos de algunos países, así como subsidió nuevas contribuciones teóricas e influenció, especialmente en América Latina, la concepción de educación popular durante los años 60 del siglo XX. En este artículo el objetivo es analizar la influencia de la educación de Paulo Freire en diferentes contextos, a partir de sus andanzas por el mundo. Se trata de un estudio bibliográfico que incluye obras de Paulo Freire y autores que estudian su pensamiento educativo en Brasil y otros países. En este artículo presentamos a Paulo Freire como inspirador del movimiento de liberación y provocamos el debate acerca de la influencia de la educación popular de Paulo Freire en diferentes contextos sociales, culturales y educativos.

Palabras-clave: Paulo Freire. Educación popular. Diferentes contextos. Andanzas por el mundo.

\section{NOTAS}

1) Frente de Libertação de Moçambique, movimento nacionalista constituído oficialmente em 25 de junho de 1962, na capital da Tanzânia (IVALA, 2000, p. 141).

2) Políticos e intelectuais responsáveis pela luta, libertação e independência de seus países. Guiné e Cabo Verde (Amilcar Cabral) e Tanzânia (Julius Nyerere).

\section{REFERÊNCIAS}

ARAÚJO, P. C. de A. Educação intercultural: encontro entre culturas, diálogo de saberes. João Pessoa: UFPB, 2004. Disponível em: <http://www.paulofreire.org.pe>. Acesso em: 12 jun. 2010.

BRANDÃO, C. R. Educação Popular. São Paulo: Brasiliense, 1984.

A educação popular na escola cidadã. Petrópolis, RJ: Vozes, 2002.

BRAÇO, A. D. O pensamento de Paulo Freire e os processos libertários na África. In: VIEIRA, A.; BATALLOSO, J. M.; MORAES, M. C. (Org.). A esperança da pedagogia: Paulo Freire - consciência e compromisso. Brasília: LIBERLIVRO, 2012. 
CANDAU, V. M. Interculturalidade e educação na América Latina e no Brasil: saberes, atores e buscas. Rio de Janeiro: PUC, 2008 (mimeo).

et al. Multiculturalismo e educação: a construção de uma perspectiva. In: CANDAU, V. M. Sociedade, educação e cultura(s): questões e propostas. Petrópolis-RJ: Vozes, 2002.

CARRILLO, A. T. Educación Popular y nuevos paradigmas: desde la producción del CEAAL entre 2004 y 2008. In: La Piragua: Revista Latinoamericana de educación y política, Panamá, n. 28, 2009.

. La educación popular: trayectoria y actualidad. Venezuela: Editorial El Búho Ltda, 2011.

FLEURI, Reinaldo. Intercultura e Educação. In: Revista Brasileira de Educação. Rio de Janeiro, n. 23. Maio/Jun/Jul/Ago, 2003.

FREIRE, A. M. A. Paulo Freire: uma história de vida. Indaiatuba, SP: Villa das Letras, 2006. FREIRE, P. Cartas a Guiné-Bissau: registros de uma experiência em processo. 4. ed. Rio de Janeiro: Paz e Terra, 1978.

. Ação cultural para a liberdade e outros escritos. 6. ed. Rio de Janeiro: Paz e Terra, 1982.

. Pedagogia da Esperança: um reencontro com a Pedagogia do oprimido. 2. ed. Rio de Janeiro: Paz e Terra, 1993a.

. Política e educação. São Paulo: Cortez, 1993b.

. Professora sim tia não: cartas a quem ousa ensinar. 2. ed. São Paulo: Olho D’Água, 1993c.

Pedagogia da indignação: cartas pedagógicas e outros escritos. 6. ed. São Paulo: UNESP, 2000.

. Liberdade cultural na América Latina. In: STRECK, D. R. (Org.). Fontes da Pedagogia Latino-Americana: uma antologia. Belo Horizonte: Autêntica, 2010.

;BETTO, F. Essa escola chamada vida: depoimentos ao repórter Ricardo Kotscho. 2. ed. São Paulo: Ática, 1985a.

;FAUNDEZ, A. Por uma Pedagogia da Pergunta. Rio de Janeiro: Paze Terra, 1985b.

;MACEDO, D. Alfabetização: leitura do mundo, leitura da palavra. Rio de Janeiro: Paz e Terra, 1990.

GADOTTI, M. Paulo Freire 90 anos: lembranças pessoais e comentários. Revista E-curriculum, São Paulo, v. 7, n. 3, dez. 2011.

GIROUX, H. Paulo Freire e a Política do Pós-Colonialismo. In: MCLAREN, P.; LEONARD, P.; GADOTTI, M. (Org.). Paulo Freire: poder, desejo e memórias da libertação. Porto Alegre: ArtMed, 1998. 
GUSTSACK, F. Diferença. In: STRECK, D.; REDIN, E.; ZITKOSKI, J. J. (Org.). Dicionário Paulo Freire. Belo Horizonte: Autêntica, 2008.

HERNÁNDEZ, I. Educação e sociedade indígena: uma aplicação bilíngue do método Paulo Freire. São Paulo: Cortez, 1981.

IVALA, A. Z. Experiências de alfabetização de adultos em Moçambique: a proposta freireana. In: SAUL, A. M. (Org.). Paulo Freire e a formação de educadores: múltiplos olhares. São Paulo: Articulação Universidade/Escola, 2000.

JARA, O. El reto de teorizar sobre la práctica para transformarla. In: GADOTTI, M.; TORRES, C. A. (Org.). Educação popular: utopia latino-americana. São Paulo: Cortez: EDUSP, 1994.

Paulo Freire, filósofo de la transformación de la historia. La Piragua: Revista Latinoamericana de educación y política, Panamá, n. 28, 2009.

MCLAREN, P. Paulo Freire é o mais importante educador crítico lido nos EUA. Revista do Instituto Humanitas Unisinos On line. São Leopoldo, RS, ano VII, n. 223, jun. 2007.

MICHEL, G. Votán Zapata: filósofo de la esperanza. México, DF: Rizoma, 2001.

MORETTI, C. Z. Subcomandante Insurgente Marcos: educação rebelde, autônoma e zapatista. In:STRECK, D. R. (Org.). Fontes da Pedagogia Latino-Americana: uma antologia. Belo Horizonte: Autêntica, 2010.

NÓVOA, A. Paulo Freire (1921-1997): a “inteireza" de um pedagogo utópico. In: APPLE, M.W.; NÓVOA, A. (Org.). Paulo Freire: política e pedagogia. Portugal: Porto Editora, 1998.

OLIVEIRA, I. A. de. Leituras freireanas sobre educação. São Paulo: UNESP, 2003.

. A contribuição da educação popular de Paulo Freire para a educação intercultural no Brasil. Rio de Janeiro: PUC-RIO, 2010. (mimeo)

RIVERO, J. Alfabetização e educação de jovens e adultos na América Latina, direito humano fundamental e fator essencial de equidade social. In: RIVERO, J.; FÁVERO, O. Educação de Jovens e Adultos na América Latina: direito e desafio de todos. Brasília, DF: UNESCO; São Paulo: Moderna, 2009.

SCOCUGLIA, A. C. A história das idéias de Paulo Freire e a atual crise de paradigmas. João Pessoa: Editora Universitária, 1997.

. A progressão do pensamento político-pedagógico de Paulo Freire. In:TORRES, C. A. (Org.). Paulo Freire y la agenda de la educación latinoamericana en el siglo XXI. Buenos Aires: CLASCO, 2001.

SERNA, J. L. A. Un diálogo: educación popular e interculturalidad experiencias, desafíos y prospectiva. La Piragua: Revista Latinoamericana de educación y política, Panamá, n. 28, 2009.

SOUZA, João Francisco de. Atualidade de Paulo Freire: contribuição ao debate sobre a educação na diversidade cultural. Recife: Bagaço; Núcleo de Ensino, Pesquisa e Extensão em Educação de Jovens e Adultos e em Educação Popular da UFPE (NUPEP), 2001. 
STRECK, D. R. Paulo Freire e a consolidação do pensamento pedagógico na América Latina. In: STRECK, D. R. (Org.). Fontes da Pedagogia Latino-Americana: uma antologia. Belo Horizonte: Autêntica, 2010.

TORRES, C. A. Grandezas y miserias de la educación latinoamericana del siglo veinte. In: (Org.). Paulo Freire y la agenda de la educación latinoamericana en el siglo XXI. Buenos Aires: Consejo Latinoamericano de Ciencias Sociales (CLACSO), 2001.

WALSH, C. Interculturalidade crítica e pedagogia decolonial: in-surgir, re-existir e re-viver. In: CANDAU, V. M. (Org.). Educação intercultural na América Latina: entre concepções, tensões e propostas. Rio de Janeiro: 7 Letras, 2009. p. 12-43.

ZITKOSKI, J. J. Paulo Freire \& a educação. Belo Horizonte: Autêntica, 2006.

IVAnilde Apoluceno de Oliveira: Doutora em Educação (Currículo) pela Pontifícia Universidade Católica de São Paulo (PUC-SP). É membro da Associação Nacional de Pós-Graduação e Pesquisa em Educação. Coordena o Núcleo de Educação Popular Paulo Freire da Universidade do Estado do Pará (UEPA). Coordena o Programa de Pós-Graduação em Educação da UEPA. Atua na área de Educação, com ênfase em Filosofia da Educação, Educação Popular e Educação Inclusiva. Em seu currículo Lattes os termos mais frequentes na contextualização da produção científica, tecnológica e artístico-cultural são: educação, educação especial, educação de jovens e adultos, inclusão, educação popular, filosofia, Filosofia da Educação e ética.

E-mail: nildeapoluceno@uol.com.br

TÂnia Regina Lobato dos Santos: Doutora em Educação: História, Política, Sociedade pela Pontifícia Universidade Católica de São Paulo (PUC-SP). É professora Titular da Universidade do Estado do Pará do Curso de Pedagogia, do Programa de Mestrado em Educação (CCSE-UEPA). Coordena o Curso de Especialização em Educação Infantil na UEPA. Atualmente é vice-coordenadora do Programa de Mestrado em Educação (PPGED-CCSE-UEPA). Tem experiência na área de Educação, especialmente com a formação de professores (inicial e continuada), e desenvolve pesquisas voltadas para políticas públicas e formação de professores, educação infantil, educação popular.

E-mail: tanialobato@superig.com.br 